East African Medical Journal Vol. 78 No. 3 March 2001

CHARACTERISATION OF VIBRIO PARAHAEMOLYTICUS ISOLATED FROM FISH IN KENYA

M.M. Kagiko, BVM, MSc, PhD, W.A. Damiano*, BVM, MSc and M.M. Kayihura, BVM, MSc., Department of Public Health, Pharmacology and Toxicology, University

of Nairobi, P.O. Box 29053, Nairobi, Kenya.

*Deceased

Request for reprints to: Prof. M.M. Kagiko, Department of Public Health, Pharmacology and Toxicology, University of Nairobi, P.O. Box 29053, Nairobi - Kenya

\title{
CHARACTERISATION OF VIBRIO PARAHAEMOLYTICUS ISOLATED FROM FISH IN KENYA
}

\author{
M.M. KAGIKO, W.A. DAMIANO and M.M. KAYIHURA
}

\begin{abstract}
Background: Acute gastroenteritis associated with fish has been reported since 1951 but is gaining importance with increase in fish consumption in Kenya. The causative agent is Vibrio parahaemolyticus. The importance of this organism is increasing due to the rise in the incidence of outbreaks of food poisoning related to it.

Objective: To isolate and characterise local strains of Vibrio parahaemolyticus from sea and fresh-water fish.

Design: A prospective study.

Setting: Three lakes, a river, a dam and the Kenyan coastline.

Subjects: Water and fish samples collected from the study sites.

Main outcome measures: Isolation of Vibrio parahaemolyticus on glucose-salt- teepol broth (GTSB), and triphenyltetrazolium chloride soya tryptone (TSAT) and several biochemical media, testing the pathogenicity for the isolates by Kanagawa phenomenon and testing the plasmids profiles, coagglutination sensitivity to antimicrobial substance using standard methods.

Results: Twenty nine isolates $(4 \%)$ were obtained from a total of 666 samples screened, twenty seven of which were isolated from 62 coastal samples. They were Kanagawa negative although their plasmid profiles and sensitivity to antimicrobials varied.

Conclusion: There is need to recognise $V$. parahaemolyticus as a potential problem due to the increase in consumption of fish as an alternative source of protein.
\end{abstract}

\section{INTRODUCTION}

Vibrio parahaemolyticus was first isolated by Fujino et al (1) and is known to cause acute gastroenteritis(2). Vibrio parahaemolyticus belongs to a group of halophilic vibrios(3) and is present in coastal and estuarine waters, sediments and planktons as well as on and in marine fishes, crustaceans and molluscs in many parts of the world(4). Baross and Liston(5) observed that these vibrios prefer coastal waters to deep ocean waters because of the high organic matter content of in-shore waters. From their experiments, Sakar et al (6) concluded that irrespective of their origin (marine or fresh water) fishes provided an ideal substrate for the survival and proliferation of $V$. parahaemolyticus. Baumann et al(7) postulated that the sodium requirement by $V$. parahaemolyticus varies with the reservoir substrate, hence it can survive well in conditions where the salt concentration may be equal to physiological concentration.

Outbreaks of food poisoning in Japan in 1951(1) brought to light the fact that $V$. parahaemolyticus is a human enteric pathogen. Subsequently, many investigators from all parts of the world have examined the occurrence of this organism in natural environment and human patients $(2,6,8,9)$. Many factors influence the epidemiology of this disease. These include the temperature of the marine water, with the numbers of the pathogen rapidly declining at temperatures below $15^{\circ} \mathrm{C}(3)$.

A marked seasonality of the disease has been noted in the USA(10) and Japan(2) in which outbreaks occurred almost exclusively during the warm summer and early fall month. Transmission from man to man has been reported but sewage from patients may pollute the coastal waters and keep a cycle of man-water-seafood-man in circulation(11), an observation which has been disputed(8) and replaced with a proposal that gastroenteritis caused by $V$. parahaemolyticus is exclusively due to consumption of contaminated food, usually raw or cooked sea food. This is not exhaustive as Sircar et al(12) reported in an interview of 60 patients of $V$. parahaemolyticus gastroenteritis that one third of them denied having eaten fish or shellfish during the previous seven days.

Clinically, this organism causes intestinal(2) and extra intestinal infections in man. For gastroenteritis, two syndromes have been observed(8). One presents with diarrhoea, abdominal cramps, nausea, vomiting, headache, fever and chills, with temperatures rarely exceeding $38.9^{\circ} \mathrm{C}(10)$. This type is usually mild and self limiting, with a median duration of three days(8) although severe cases of dehydration, hypotension and acidosis have been 
reported(13). The second syndrome is a dysenteric type which is characterised by mucoid or sanguinous stool(14).

The extra intestinal syndrome may take the form of septicaemia(15), synovitis, wound infections progressing into gangrene and endotoxic shock(16). Eye infections have been known to occur(17).

Among the exotoxins produced by $V$. parahaemolyticus the simple protein with molecular weight of 42,000 Da thermostable direct haemolysin (TDH) associated with Kanagawa positivity, has been extensively studied. A thermostable haemolytic (TLH) toxic can be detected in culture filtrates of Kanagawa positive strains.

Scanty reports of the organisms isolation in fresh water ponds and rivers are available but its existence in Kenyan lakes, where about $90 \%$ of total fish in Kenya is caught, has not been reported. We undertook to isolate $V$. parahaemolyticus from fish lakes and coastal waters of Kenya and characterise the isolates by studying their toxic production, antimicrobial susceptibilities, plasmid profiles and their antigens specificity.

\section{MATERIALS AND METHODS}

Fish which had been freshly caught were obtained from various ecological zones ranging from marine, lacustrine to riverine areas spread throughout Kenya (Table 1). Surface, gills, intestines and kidneys were swabbed and the swab placed in a bijou bottle containing Stuarts medium (lab M). Universal bottles were used to sample water at the fish sampling sites. The samples were transported in a cool box and stored at $4^{\circ} \mathrm{C}$ before analysis.

Table 1

Places and sizes of samples collected

\begin{tabular}{lrr}
\hline Place & \multicolumn{2}{c}{ No. of samples collected } \\
& Fish & Water \\
\hline Lake Victoria & 347 & 15 \\
Lake Turkana & 98 & 5 \\
Lake Naivasha & 107 & 5 \\
River Sombeli (L. Magadi) & 4 & 5 \\
Masinga Dam & 74 & 5 \\
Coastal Waters & 93 & 5 \\
\hline Total & 723 & 40 \\
\hline
\end{tabular}

Two liquid enrichment media (alkaline peptone water and glucose salt-teepol broth) were prepared and $3 \%$ sodium chloride added. Fish homogenates and swabs were inoculated and incubated at $37^{\circ} \mathrm{C}$ overnight before further transfer to thiosulfatecitrate-bile-salt sucrose agar(TCBS).

Direct culture was done on TCBS and triphenyletrazolium chloride soya tryptone(TSAT) agar. Confirmation was by use of a vibriostatic agent (compound 0/129), oxidation-fermentation test and biochemical reaction in sugars and amino acids.

The pathogenicity of $V$. parahaemolyticus isolate was assayed by testing for the Kanagawa phenomenon using three control strains on Wagatsuma blood agar. The haemolytic activity was determined according to the standard methods. Antimicrobial resistance was tested on Mueller- Hinton agar (Difco) using single antimicrobial tablets. Each cell inoculum contained $10^{5}$ $\mathrm{cfu} / \mathrm{ml}$. The battery of antimicrobial tablets (neosensitabs, A/S
Rosco Taastrup, Denmark) consisted of ampicillin, bacitracin, chloramphenicol, fucidin, nalidixic acid, neomycin, nitrofuran, pencillin (low). oxacillin, streptomycin, trimethoprim, trimethoprim-sulfamethoxazole, tetracycline and sulphonamides.

Plasmid profiles of the isolates were studied using a procedure which involved breakdown of the cell to release plasmid and subsequent separation by electrophoresis and staining with ethidium bromide. A reference $E$. coli $\mathrm{V} 157$ with eight plasmids was used as a marker. Ouchterlony's double diffusion test was carried out on microscope slides and placed in a humid chamber for 24 hours at room temperature after which they were stained by Coomasie brilliant blue dye (Sigma Chemicals, St. Louis, USA)

Slide coagglutination for somatic $\mathrm{O}$ antigen was carried out using sera raised in our laboratory animals (rabbits) inoculated with our isolates and with a reference strain serotype 07: K19. Stabilised Staphylococcus aureus (Cowan 1) were coated with the produced rabbit antiserum and with a two per cent suspension of the isolates. After five minutes of rocking, the slide was viewed using a microscope against a dark background.

\section{RESULTS}

A total of 723 sample were collected out of which 666 were screened for $V$. parahaemolyticus yielding $29(4 \%)$ isolates. An isolation rate of $44 \%$ was observed in coastal specimens. Isolation from other areas was insignificant being only two isolates out of the remaining samples (Table 2).

Table 2

Isolation of $V$. parahaemolyticus species from fish and water from various areas in Kenya

\begin{tabular}{llrr}
\hline Area sampled & Types of & \multicolumn{2}{c}{$\begin{array}{c}\text { V.parahaemolyticus } \\
\text { Isolates }\end{array}$} \\
& samples collected & $\begin{array}{r}\text { \% isolation } \\
\text { specimens }\end{array}$ \\
Coastal water & Fish, water & $25 / 57$ & 44 \\
L. Naivasha & Fish, water & $2 / 5$ & 40 \\
L. Victoria & Fish, water & $1 / 94$ & 1 \\
& & $0 / 5$ & 0 \\
Masinga Dam & Fish, water & $1 / 310$ & 0.3 \\
& & $0 / 15$ & 0 \\
L. Turkana & Fish, water & $0 / 74$ & 0 \\
& & $0 / 5$ & 0 \\
River Sombeli & Fish, water & $0 / 87$ & 0 \\
(Magadi) & & $0 / 5$ & 0 \\
\hline & & $0 / 4$ & 0 \\
& & $0 / 5$ & 4
\end{tabular}

All the 29 isolates were negative for hacmolysis in Wagatsuma medium as tested against the positive and negative reference strain.

Antimicrobial sensitivity of the isolates showed that all were sensitive to seven and resistant to four of the test antimicrobials(Table 3). Intermediate sensitivity was shown to neomycin and nitrofuran with some isolates being sensitive while others were resistant. Resistance to trimethoprim was quite low $(5 \%)$.

Only two out of the total isolates were found to contain plasmids whose molecular weight varied from 1 4.34 MDa. Immunodiffusion on Ouchterlony's agar plate 
showed that strong precipitation lines of identity were given by antisera raised against the somatic " $\mathrm{O}$ " antigens from the third bleeding.

Table 3

Frequency of drug resistance among the 20 isolates of V. parahaemolyticus

\begin{tabular}{lcr}
\hline $\begin{array}{l}\text { Antimicrobial } \\
\text { agent tested }\end{array}$ & $\begin{array}{r}\text { No. of resistant } \\
\text { isolates }(\mathrm{n}=20)\end{array}$ & $\begin{array}{r}\text { \% of resistant } \\
\text { isolates }\end{array}$ \\
\hline $\begin{array}{l}\text { Ampicillin }(33 \mathrm{ug}) \\
\text { Doxycycline }(80 \mathrm{ug})\end{array}$ & 19 & 95 \\
Chloramphenicol $(60 \mathrm{ug})$ & 0 & 0 \\
Fucidin (400 ug) & 0 & 0 \\
Nalidixic acid (130 ug) & 20 & 100 \\
Neomycin (120 ug) & 0 & 70 \\
Nitrofuran (260 ug) & 14 & 60 \\
Penicillin (low) $(5 \mathrm{ug})$ & 12 & 100 \\
Oxacillin $(5 \mathrm{ug})$ & 20 & 100 \\
Streptomycin $(5.2 \mathrm{ug})$ & 20 & 0 \\
Trimethoprim $(5.2 \mathrm{ug})$ & 0 & 5 \\
Trim + sulpha $(5.2 \pm 240 \mathrm{ug})$ & 1 & 0 \\
Tetracycline $(80 \mathrm{ug})$ & 0 & 0 \\
Sulphonamides $(240 \mathrm{ug})$ & 0 & 0 \\
\hline
\end{tabular}

Out of twenty isolates tested, only five $(25 \%)$ were serotypable. Three different serotypes were found; -02 ; $\mathrm{K} 28 ; 03: \mathrm{K} 29$ and 04: K42 distributed in the ratio of 2.2:1 among the five isolates. In the slide agglutination tests, four $(14 \%)$ of the 29 isolates were able to form a clear carpet of coagglutinated cells.

\section{DISCUSSION}

Nearly all the isolates were obtained from seafish unlike Binta et al(18), and Ijumba(19), who isolated $V$. parahaemolyticus from shellfish as well. Vibrio parahaemolyticus were isolated in two inland lakes fish samples at a low rate. This was probably due to dilution or seasonal variations. Another possibility is that our isolates belong to sea water environ and were introduced transciently in seafish crates in a central market handling both sea and fresh water fishes. Other investigators have reported isolations from streams which drain into fresh water lakes $(6,20)$.

In agreement with other findings, all the isolates, being environmental, were Kanagawa negative. Whereas Kanagawa positivity has been associated with enteropathogenicity, outbreaks of this disease have been traced to seafish, shell-fish and fresh water fish $(9,19)$ the natural reservoirs of Kanagawa negative strains. It is therefore possible that infections due to these strains do occur in Kenya but are either misdiagnosed or remain unreported as the infection is usually mild and self limiting.

The antibiogram of these isolates generally agrees with other reported antibiograms $(21)$. The minor variations observed cannot be considered significant. Conjugal Rplasmid coding for multiple drug resistance have been reported(22). The two strains found to bear light plasmids showed antibiograms similar to other non-plasmid bearing isolates. Cryptic plasmids have been reported in $V$. parahaemolyticus $(23)$ but their plasmids ranged in molecular weight from 6.2 - 7.5 MDa. Only two of the 29 V. parahaemolyticus isolates contained plasmids which is a low plasmid carriage as compared to other reports(23). The variations might be due to the difference in sources and place of the isolates and the usage of antibiotics which might induce acquisition of plasmids. Thus, the use of plasmid profiles in epidemiology is of limited value here.

The results of the slide agglutination test showed that only $14 \%$ of the isolates were identified by the antiserum. Of the typable isolates, only one had the same serotype as the reference strains $(0.4: \mathrm{K} 42)$ used to raise the antiserum. "O" antisera of V. parahaemolyticus are not very specific for species as they cross-react with other vibrios. In spite of increasing the sensitivity, this test lacks specificity and is of limited use in epidemiological surveys and as a rapid identification tool.

Of a total of twenty isolates, only five could be serotyped. This is a low rate compared to similar results obtained by Nair et al(24) who reported typability of $32.8 \%$ for non marine fish and water sample isolates, $40.7 \%$ for marine fish and water isolates, as well as $50.9 \%$ of the 324 environmental isolates of $V$. parahaemolyticus (24). However, they concluded that a high number of untypable strains exist in environmental strains as compared to clinical isolates. they also found that fresh water isolates have the largest numbers of untypable strains(24). This is in agreement with the results obtained where the two fresh water isolates were untypable. Two of the typable isolates were found to be $02: \mathrm{K} 28$. Serotype 01 : $\mathrm{K} 56$, more associated with clinical isolates, was not found in any of our isolates.

It is concluded that $V$. parahaemolyticus is present in fish, especially sea fish, in Kenya, and could pose health problems in view of the increase in consumption of fish in this country. It is thus recommended that in view of the importance that the Government is now attaching to marine products both for local and export markets, there is need for further research to determine the extent of the problem. The public should be well informed on ways to handle marine products and the dangers associated with consumption of such raw marine products.

\section{ACKNOWLEDGEMENTS}

To the German Academic Exchange Services (DAAD) and NORAD for the funding as well as Dr. Nair, G.B., of the National Institute of Cholera and Enteric Disease, Calcutta, India for providing reference strains of $V$. parahaemolyticus.

\section{REFERENCES}

1. Fujino, T., Kudo, Y., Nakanda, D., Aoyama, A., Fukai, K, Mukai, T. and Uecho, T. On bacteriological examination of shirasu food poisoning. J. Jpn. Ass. Infect. Dis. 1951; 35:11.

2. Miwatani, T. and Takeda, Y. Vibrioparahaemolyticus: acausative bacterium of food poisoning Tokyo Publishing Co. Saikon, 1976. pp. 23. 
3. Barrow, G.I. and Miller, D.C. Vibrio parahaemolyticus and seafoods. In: Microbiology in Agriculture, fisheries and food; ed Skinner and Carr. Academic Press. 1976; pp. 181-193.

4. Thompson, C.A., Vanderzant, C. and Roy, S.M. Relationship of Vibrio parahaemolyticus in oysters, water and sediment and bacteriological and environmental indices. J. Fd. Sci. 1976; 41:117-122.

5. Baross, J. and Liston, J. Occurrence of Vibrio parahaemolyticus and related haemolytic vibrios in marine environments of Washington State. Appl. Microbiol. 1970; 20:179-186

6. Sarkar, B.L., Nair, G.B., Baner Jee, A.K. and Pal, S.C. Seasonal distribution of Vibrio parahaemolyticus in freshwater environs and in association with freshwater fishes in Calcutta. Appl. Environ. Microbiol. 1985; 49:132-I36.

7. Baumann, P., Furnis, A.L. and Lee, J.V. Genus Vibrio in N.G. Krieg and Holt, J.C. (eds) Bergeys Manual of Systematic Bacteriology. Vol. 1, 1984; pp. 518-538.

8. Blake, P.A., Weaver, R.E. and Hollis, D.G. Diseases of humans other than cholera caused by vibrios. Ann. Rev. Microbiol. 1980; 34:341-367.

9. Mhalu, F.S., Mbwama, J., Nyambo, R. and Yusufadi, A.H. Cholera-like disease due to Vibrio parahaemolyticus. J. trop. Med. Hyg. 1982; 55:169

10. Barker, W.H. Vibrio parahaemolyticus, outbreak in the United States. Lancet. 1974; 1:551-554

11. Deb, B.C. Studies on Vibrio parahaemolyticus infections in Calcutta as compared to cholera infection. Prog. Drug. Res. Trop. $1975 ; 19: 490-502$

12. Sircar, B.K., De, S.P., De, S.P., Sengupta, P.G., Mondal, S., Sen, D., Deb, B and Pal, S.C. Studies on transmission of Vibrio parahaemolyticus infection in Calcutta communities. Indian $J$. Med. Res. 1979; 70:898-907.

13. Mazumdes, D.N.G., Ghosh, A.K., De, S.P. and Sircar, B.K. Vibrio parahaemolyticus infection in man. Indian J. Med. Res. 1977; 66:180-188.
14. Hughes, J.M., Boyes, J.M., Aleem, A.R., Wells, J.G., Mizanur, A.S. and Curlin, B. Vibrio parahaemolyticus enterocolitis in Bangladesh: Report of an outbreak. Amer. J. trop. Med. Hyg. 1978; 27:106-112.

15. Tay, L. and Yu, M. Vibrioparahaemolyticus in oysters, water and sediment and bacteriological and environmental indices. J. Food Sci. 1978; 41:117-122.

16. Rowland, F.P. Leg gangrene and endotoxic shock due to Vibrio parahaemolyticus. An infection acquired in New England Coastal water. N. Engl. J. Med. 1970: 282:1306.

17. Tacket, C.O., Barrett, T.J., Sanders, G.E. and Blake, P.A. Panophthalmitis caused by Vibrio parahaemolyticus. J. Clin. Microbiol. 1982; 16:195-196.

18. Binta, G.M., Tjaberg. T.B. and Nyaga, P.N. Market fish hygiene in Kenya. J. Hyg. Camb. 1982; 87:47.

19. Ijumba, P.K. Occurrence of Vibrio parahaemolyticus in Tanzania coastal waters and fish. East Afr. Med. J. 1984; 61:675-680.

20. Waiyaki, P.G., Ngugi, J.M., Sang, W.K. and Ichoroh, C.G. Isolation of enteropathogens from community water sources in Nyanza province, Kenya. Paper no. 85/05 in proceedings of KEMR I Seminar, 1985

21. Farmer, J.J., Hickmann-Brenner, F.W. and Kelly, M.T. Vibrio. In: Manual of Clinical Microbiology 4th ed. 1985; pp. 282-301.

22. Arai, T., Hamashima, H. and Hasegawa, H. Isolation of a new drug-resistance plasmid from a strain of Vibrioparahaemolyticus. Microbiol. Immunol. 1985; 29:103-112.

23. Guerry, P. and Colwell. Isolation of cryptic plasmid deoxyribonucleic acid from Kanagawa positive strains of Vibrio parahaemolyticus. Infect Immun. 1977; 16:328-334.

24. Nair, B.G., Sarkar, B.L., Abraham, M. and Pal, S.C. Serotypes of Vibrio parahaemolyticus isolates from hydrobiologically dissimilar aquatic environments. Appl. Environ. Microbiol. 1985; 9:724-726. 